\title{
PREVENTIVE CONSERVATION STRATEGIES FOR SUSTAINABLE URBAN \\ POLLUTION CONTROL IN MUSEUMS
}

Nigel Blades, May Cassar, Tadj Oreszczyn and Ben Croxford

\begin{abstract}
The last 40 years has seen major changes in the sources and concentrations of urban pollution $\left(\mathrm{NO}_{2}, \mathrm{SO}_{2}, \mathrm{H}_{2} \mathrm{~S}\right.$ and particles). During this time, research has advanced our understanding of the impact of pollutants on objects in urban museums. As a consequence, pollutant control has become an important aspect of preventive conservation. There is also increased awareness of the need for pollution control strategies that are sustainable at an organisational and global level. This paper prepared by a chemist, conservator and two building scientists reviews strategies for minimising the impact of urban pollution on museum collections. The results of new research funded by the UK government identify current (1999) internal pollution levels in both naturally ventilated and air-conditioned museums with particle and gaseous filtration, in relation to external concentrations, ventilation strategies and the characteristics of the internal fabric and finishes of these buildings.
\end{abstract}

\section{INTRODUCTION}

During recent decades the UK urban environment has seen the benefit of a massive decline in emissions of $\mathrm{SO}_{2}$ and smoke due to a reduction in coal burning. At the same time other pollutants have become more prominent. $\mathrm{NO}_{2}$ emissions in cities have increased due to an increase in road traffic [1]. $\mathrm{O}_{3}$, which arises from photochemical reactions involving vehicle emissions, is also on the increase and there is evidence that $\mathrm{H}_{2} \mathrm{~S}$ emitted from cars fitted with catalytic converters may also be increasing [2]. Whilst emissions of coal smoke have declined, diesel soot from public service vehicles and lorries have become a significant source of particulate pollution in cities. 
How external pollutant concentrations translate into poor air quality inside buildings is the subject of much concern. Historically buildings have been ventilated with "fresh" outdoor air in order to prevent the build up of internally generated pollutants in particular bioeffluents. Ventilation standards such as CIBSE's '8 litres/second/person' [3] have been based on the levels of fresh air required to disperse human odour to acceptable levels. Since we spend some $90 \%$ of our time indoors, ventilation has an impact not only on comfort but also health. Modern 'fit-out' materials and equipment in buildings can generate pollutants that may be harmful to health. Building owners therefore have to balance the problems from internally and externally generated pollutants when setting ventilation rates. Additionally, there is increasing pressure to control building environments in a globally sustainable manner.

Museum managers have the dual responsibility to protect objects from damage as well as to maintain the health and comfort of visitors and employees. Where pollution control is concerned, this can demand significant resources, depending on what damage threshold is set for objects. If the standard is that any damage is unacceptable, then the museum would have to control pollution to a level that is several orders of magnitude below the human health threshold. Standards currently in use [4,5] tend to prescribe realistically achievable pollution levels, implying that some damage is accepted as inevitable. At many UK museums pollution control is either ruled out as impossibly expensive or air-conditioning without carbon filtration is installed. However, museums may take steps to control pollution within display cases or storage boxes. In the UK, art galleries are the organisations most likely to install air-conditioning with filtration.

This paper offers possible pollution control strategies, some familiar and others more novel, which could be used to achieve, or better, currently accepted standards of pollution control. The strategies are based on the results of intensive pollution measurement campaigns at 
five UK museums.

Before different control strategies could be investigated it was essential first to establish current pollution concentrations in the study museums. Five museums were selected for monitoring to give a range of different museum environments. The Museum of London is fully air-conditioned with carbon filtration; the Theatre Museum is fully air-conditioned but has zones with and without carbon filtration; the Victoria \& Albert Museum whilst largely naturally ventilated, has some galleries air-conditioned with carbon filtration; and The Manchester Museum and Dreadnought Study Collection Centre of the Horniman Museum are entirely naturally ventilated.

Monitoring campaigns were carried out in winter and in summer at ten sites in each museum in order to characterise the pollution in and around the buildings and to determine how the building fabric and services affected internal concentrations. $\mathrm{NO}_{2}, \mathrm{SO}_{2}, \mathrm{H}_{2} \mathrm{~S}, \mathrm{O}_{3}$ (summer only) and particles were monitored. In museum buildings gases such as $\mathrm{NO}_{2}, \mathrm{SO}_{2}$ and $\mathrm{O}_{3}$ will have exclusively external sources, whereas $\mathrm{H}_{2} \mathrm{~S}$ and particles could come from both indoor and outdoor sources, and may require a different approach to their control. Due to space considerations, particles will not be discussed in this paper.

It was necessary to monitor in both winter and summer because externally generated pollutants can be subject to seasonal variations in emission, generation and weather dispersal. At each museum two, and where possible three, external sites were monitored to establish the external pollutant concentrations around the museum. Inside the buildings seven or eight sites were monitored, including entrance halls, galleries and storerooms to establish the pollution 'geography' of the museum. Diffusion tubes were used to measure the pollutants because they 
are a cost-effective way of monitoring simultaneously many different sites and they give monthlong average data that reflect well the long-term exposure conditions of objects in museums. The monitoring techniques were the same as those used by Cassar et al. [6].

Pollution control strategies fall broadly into two categories, passive and active. Passive strategies require no energy to control air movement within a building whereas active strategies require some form of mechanical control of ventilation.

\subsection{Passive control strategies}

\subsubsection{Controlling pollution ingress by drawing in air from the less polluted side of a building}

In naturally ventilated buildings air moves horizontally through a building if ventilation is winddriven, or vertically if it is stack-driven. One control measure that can be undertaken is to seal the building on its most polluted side, for instance on its road frontage and to ensure that air is taken in from the less polluted side. Entrance lobbies should be fitted with double sets of doors to reduce pollutant ingress from street entrances. However, care must be taken to avoid sealing the building too tightly otherwise ventilation may be insufficient to disperse internally generated pollutants such as human odour.

Table 1. External $\mathrm{NO}_{2}$ concentrations at the front and back of two museums.

\begin{tabular}{lcc}
\hline Site & $\begin{array}{c}\mathrm{NO}_{2}(\mathrm{ppb}) \\
\text { winter }\end{array}$ & $\begin{array}{c}\mathrm{NO}_{2}(\mathrm{ppb}) \\
\text { summer }\end{array}$ \\
\hline The Manchester Museum: & & \\
Front (Oxford Road) & 28.2 & 22.5 \\
Rear of the building & 16.4 & 16.9 \\
& & \\
Victoria \& Albert Museum: & & 24.2 \\
Front (Cromwell Road) & 28.5 & 24.4 \\
Rear courtyard & 23.6 & \\
\hline
\end{tabular}


Table 1 shows data for $\mathrm{NO}_{2}$ at two museums that have frontages on busy roads. $\mathrm{NO}_{2}$ in cities comes mainly from vehicle traffic and the two roads in question are among the busiest urban streets in the UK. It is clear that, apart from the Victoria \& Albert Museum in summer, the $\mathrm{NO}_{2}$ concentration is much higher on the road frontage than at the back of the buildings. The effect is more pronounced at The Manchester Museum than the Victoria \& Albert Museum. This may be because The Manchester Museum is closer to the main road at about $3 \mathrm{~m}$ from the kerbside, whereas the Victoria \& Albert Museum is more set back at approximately $8 \mathrm{~m}$ from the kerbside. $\mathrm{NO}_{2}$ concentrations can show pronounced localised variations close to roads with heavy traffic $[7]$.

\subsubsection{Removal of pollutants by surface deposition}

Spedding [8] observed that in domestic houses the $\mathrm{SO}_{2}$ concentration was often as low as $20 \%$ of outdoors and reasoned that it was removed by deposition and chemical reaction at interior surfaces such as walls, floors and ceilings. It is because of this reactivity to materials that $\mathrm{SO}_{2}$ causes damage, yet this reactivity could also be used to remove it from the museum environment. In a series of papers Spedding studied the deposition of $\mathrm{SO}_{2}$ onto materials such as wallpaper, wood and leather and was able to calculate their affinity for $\mathrm{SO}_{2}$ [9-11].

The mechanism of removal by deposition is also very important for other reactive pollutants, such as $\mathrm{O}_{3}$, which is even more reactive than $\mathrm{SO}_{2}$. In the monitoring campaigns $\mathrm{O}_{3}$ was found in only one interior site at the surveyed museums. $\mathrm{NO}_{2}$ is less reactive than either $\mathrm{SO}_{2}$ or $\mathrm{O}_{3}$, but is still subject to removal by deposition, though to a lesser extent than the other gases. Note that removal by deposition generally involves chemical transformation of the pollutant and as such is irreversible. 
The degree of removal by deposition is dependent on: (i) chemical properties of the pollutant gas; (ii) chemical reactivity of the surfaces it comes into contact with; (iii) surface/volume ratio of the room or building; and (iv) the room or building ventilation rate. A mass balance equation [12] has been derived which predicts the indoor/outdoor pollutant ratio based on these parameters:

$$
\mathrm{I} / \mathrm{O}=\mathrm{ach} /\left(\mathrm{V}_{\mathrm{dep}}(\mathrm{S} / \mathrm{V})+\mathrm{ach}\right)
$$

where $\mathrm{I}=$ indoor concentration

$$
\begin{aligned}
& \mathrm{O}=\text { outdoor concentration } \\
& \text { ach = air exchange rate }\left(\mathrm{hr}^{-1}\right) \\
& \mathrm{V}_{\text {dep }}=\text { deposition velocity of the pollutant gas }\left(\mathrm{mhr}^{-1}\right) \\
& \mathrm{S}=\text { surface area of interior }\left(\mathrm{m}^{2}\right) \\
& \mathrm{V}=\text { interior volume }\left(\mathrm{m}^{3}\right)
\end{aligned}
$$

$\mathrm{V}_{\text {dep }}$ is a measure of how rapidly a particular material will react with a gas to remove it from the atmosphere. Note that equation (1) is only relevant for pollutants with exclusively external sources and assumes no gas phase reactions (a reasonable assumption for the pollutants involved, given that museum lighting is generally not sufficiently intense to promote photochemical reactions and $\mathrm{O}_{3}$ is absent from most interiors). Figure 1, based on equation (1), predicts pollutant $\mathrm{I} / \mathrm{O}$ ratios at different air exchange rates in various types of museum space, using values of $\mathrm{V}_{\mathrm{dep}}, \mathrm{S}$ and $\mathrm{V}$ measured at the monitored museums.

As examples of extreme low and extreme high pollution removal by deposition it is interesting to compare The Manchester Museum Mammals Gallery with the Dreadnought Study Collection Centre Halls 2 and 3.

The Mammals Gallery is a large open plan space, extending upwards though three floors 
of The Manchester Museum and contains two mezzanine floors. This part of the museum was built in 1885 and is fitted throughout with unsealed metal-framed windows. The interior surfaces are mostly stone and wood floors and painted plaster walls and ceiling. The gallery would normally be accessible though open archways to and from adjacent rooms but at the time of monitoring it was closed off to the rest of the museum, awaiting renovation.

The Dreadnought Study Collection Centre is housed in a Victorian school (1892), which was converted to a museum store in the late 1960s. Considerable time and resources have been invested in sealing the building from the ingress of particulate and gaseous pollution because the store is located in an industrial area of south London near to ongoing building and infrastructure works at the Millennium Dome site. Exterior doors have been fitted with additional entrance lobbies and most of the windows have been sealed with mastic. The internal layout has a cellular configuration with storerooms leading off two main staircases. All the storerooms are fitted with doors and doors close off the stairwells at each floor level. Halls 2 and 3 are two of the larger storerooms having wooden floors, painted brick walls and painted plasterboard ceilings. Pollution levels, ventilation rates and the room dimensions were measured at these two sites and the results are summarised in table 2.

Table 2. Comparison of $\mathrm{S} / \mathrm{V}$ ratio, ventilation rate and $\mathrm{NO}_{2} \mathrm{I} / \mathrm{O}$ ratio for The Manchester Museum Mammals Gallery, and Halls 2 and 3 at the Dreadnought Study Collection Centre

\begin{tabular}{|c|c|c|c|c|c|c|c|c|}
\hline Site & $\begin{array}{l}\text { Volume } \\
\left(\mathrm{m}^{3}\right)\end{array}$ & $\begin{array}{c}\text { Surface } \\
\text { Area } \\
\left(\mathrm{m}^{2}\right)\end{array}$ & $\begin{array}{l}\mathrm{S} / \mathrm{V} \\
\text { ratio }\end{array}$ & $\begin{array}{c}\text { Ventil- } \\
\text { ation } \\
\text { Rate } \\
\text { (ach) }\end{array}$ & $\begin{array}{c}\mathrm{NO}_{2} \\
\text { outdoor } \\
(\mathrm{ppb})\end{array}$ & $\begin{array}{c}\mathrm{NO}_{2} \\
\text { indoor } \\
(\mathrm{ppb})\end{array}$ & $\begin{array}{c}\mathrm{NO}_{2} \\
\mathrm{I} / \mathrm{O} \\
\text { ratio }\end{array}$ & $\begin{array}{c}\text { Removal } \\
\text { constant } \\
\mathrm{V}_{\text {dep }}(\mathrm{S} / \mathrm{V}) \\
\left(\mathrm{hr}^{-1}\right)\end{array}$ \\
\hline $\begin{array}{l}\text { Manchester Museum } \\
\text { Mammals Gallery }\end{array}$ & 2925 & 2194 & 0.75 & 0.7 & 21.8 & 14.3 & 0.66 & 0.4 \\
\hline $\begin{array}{l}\text { DSCC Store } \\
\text { Halls } 2 \text { and } 3\end{array}$ & 800 & 1195 & 1.49 & 0.37 & $11.8 *$ & 1.1 & 0.09 & 4.5 \\
\hline
\end{tabular}


The $\mathrm{I} / \mathrm{O}$ ratio in the store is very small compared with that in the open plan gallery. The factors in table 2 were put into equation (1) to calculate $V_{\text {dep }}(S / V)$, effectively the removal constant for the rooms. As can be seen, the value for the Dreadnought store is ten times that of the Mammals Gallery.

Pollutant removal by deposition could therefore form the basis of a strategy for passive pollution control in museums, as long as objects do not form the reactive surfaces and are protected locally. From equation (1) interventions such as increasing the interior surface areas, choosing interior surface finishes that have good absorbing properties and reducing the ventilation rate would all help to enhance pollutant surface deposition. In practice such interventions would mean, for instance, choosing a room layout consisting of a series of small rooms with interconnecting doors, instead of an open-plan layout; wall finishes of concrete, brick, or plasterboard (alkaline materials react well with acid pollutants such as $\mathrm{SO}_{2}$ and $\mathrm{NO}_{2}$ ) and carpeted floors; reducing direct ventilation from the external environment to a minimum and ensuring that fresh air has to follow a torturous path, so that it is subjected to increased surface contact which helps reduce its pollutant load. Research to investigate the effects of these interventions is currently under way.

Where it is not feasible to introduce such modifications to a museum building, vulnerable objects can be placed in rooms where control by deposition takes place, for example rooms at the heart of a building, or in display cases with low ventilation rates and whose high $\mathrm{S} / \mathrm{V}$ ratio makes them very effective at controlling external pollutants by deposition. It is inevitable that some deposition will occur to object- as well as wall-, floor- or ceiling-surfaces, but this will occur in any environment the objects are placed. Pollutant flux to a surface is proportional to the 
concentration therefore it is best to place objects in rooms with the lowest concentration. Conditions that lead to good control by deposition are those likely to be found in small rooms with low ventilation rate such as stores and archives rather than in galleries and exhibition spaces, which require a higher ventilation rate to make them habitable for large numbers of visitors. In these situations there is little alternative but to use an active system incorporating carbon filtration to remove the pollutants.

\subsection{Active Control Strategies}

Correctly installed and maintained mechanical ventilation allows greater control of air quality and ventilation rates in a building than passive control, provided that the building is well sealed. It has the following advantages for controlling pollutant levels:

1. The exact location of inlets and outlets in a naturally ventilated building are unknown. In mechanically ventilated buildings the exact location of the air inlet can be controlled therefore air can be drawn in from the least polluted site around a building. This is often at roof level, although for some pollutants, concentrations can increase above street level $[13,14]$.

2. Air can be more easily filtered before it enters a building. Mechanical ventilation overcomes the resistance of filters to the passage of air through the medium. It is therefore possible to use filters which are substantially more efficient at removing pollutants than is the case with natural ventilation where a filter with even a small pressure drop across it can substantially reduce the flow of air through it.

3. When a museum building is unoccupied ventilation can be reduced to a minimum. During opening hours ventilation can be maintained at a level just sufficient for human comfort. 
This is most easily achieved with the use of carbon dioxide sensors because the $\mathrm{CO}_{2}$ concentration is a direct indicator of the required ventilation rate per occupant.

It should be noted that normally, mechanical ventilation is installed in museums to provide better relative humidity $(\mathrm{RH})$ and temperature control for object conservation and visitor comfort [15], rather than pollutant control.

Mechanical ventilation can have the following disadvantages:

1. Increased capital and maintenance costs

2. Greater control problems during periods when plant is not operational either due to plant failure or regular maintenance.

3. Difficult to install in historic buildings. Museum buildings are often important in their own right and may not have been designed for operation with a mechanical ventilation system. Introducing large ducts to carry the air is difficult, intrusive and destructive of the original fabric, while small ducts result in a more energy intensive and thus a more expensive system to run.

\subsubsection{Effectiveness of air-conditioning systems at reducing pollutant concentration}

The effectiveness of air-conditioning systems at reducing pollution concentration depends on whether carbon filtration is installed. Monitoring of museums with air-conditioning and carbon filtration showed that these were generally effective at removing $\mathrm{SO}_{2}, \mathrm{O}_{3}$ and $\mathrm{H}_{2} \mathrm{~S}$, and could substantially reduce the concentration of $\mathrm{NO}_{2}$. However, at the Theatre Museum Picture Gallery, which had air-conditioning but no carbon filtration, the concentrations of $\mathrm{NO}_{2}$ and $\mathrm{H}_{2} \mathrm{~S}$ were almost as high as external levels, and higher than concentrations in some of the naturally 
ventilated museums. This result was confirmed by interventions carried out at the Museum of London and Victoria \& Albert Museum, in which the carbon filters were removed from the air conditioning systems and the resulting pollutant concentrations measured. The $\mathrm{NO}_{2} \mathrm{I} / \mathrm{O}$ ratios, calculated from these measurements (figure 2), confirm that higher pollutant concentrations occur in these air-conditioned spaces when there is no filtration. In these cases it appears that airconditioning increases the ventilation rate in the room, bringing in more polluted air, resulting in a worse environment than if the building were just naturally ventilated. Furthermore, there was evidence that polluted air from the Theatre Museum Picture Gallery infiltrated the Archive Store, which is supplied with carbon-filtered air from a separate plant. The two zones are only separated by glass doors, which for convenience are often left open. It is not surprising therefore that the $\mathrm{I} / \mathrm{O}$ ratios for the Archive are much greater than those in other air-conditioned carbon-filtered locations. The effectiveness of the air-conditioning pollution control system serving the Archive Store would be increased considerably by keeping the glass doors closed. The implication is that museums should think carefully before installing air conditioning without carbon filtration because it will lead to a worse environment than in naturally ventilated urban buildings.

\subsubsection{System-based filtration}

There is a wide range of commercially available air filters with very different properties. Most museums use activated carbon filters, which remove with varying efficiencies, all the gaseous pollutants studied in this project. Filter efficiency and life expectancy can be improved by impregnating the carbon with metals, which ensure that pollutants are irreversibly retained. However, filters are of little use if air entering the building does not pass through them. Therefore the filtration system must be designed to prevent air bypassing the filters. Such bypass 
would allow unfiltered air to enter the building via the air intake system. Also, unfiltered air must be prevented from leaking into the building through gaps in the external fabric. Double sets of doors, which create draught lobbies or rotating doors, can substantially reduce infiltration. Figure 3 shows that air infiltration can have a substantial impact on the pollution $\mathrm{I} / \mathrm{O}$ ratio of an air-conditioned carbon-filtered museum. If only part of a museum is to be conditioned it must be physically separated from the other parts of the building.

The lifetime of a carbon filter is determined by both the quantity and type of activated carbon used in filter manufacture together with the concentration of pollutants in the incoming air. Therefore measures which reduce incoming pollution will increase filter lifetime. Reducing the quantity of external air entering the system will extend filter life and improve efficiency. The quantity of air passing through an air conditioning system is normally determined by the heating or cooling requirements of a building and not the need for fresh air. For this reason many systems do not operate on $100 \%$ fresh air intake but they re-circulate a substantial portion. This recirculated air should also pass through the filters, as this further reduces pollution concentration (figure 3) and helps to reduce that of internally generated pollutants. The quantity of re-circulated air should be high for efficient pollutant control. However, care should be taken to provide adequate fresh air for human comfort and health.

\subsubsection{Local filtration}

When only a limited number of objects require high levels of pollution control it may be more appropriate to provide localised filtration. Figure 4 predicts the effect of a local filtration unit fitted with $99 \%$ efficient carbon filter cells running in a room which has a natural ventilation rate of 0.75 air changes hour (ach). With filtration in operation the $\mathrm{NO}_{2} \mathrm{I} / \mathrm{O}$ ratio drops from 0.3 to 
0.1 , at 5 filter unit room ach. Note there is little benefit in the filter unit operating at more than 5 ach. Figure 5 illustrates the actual effect, from monitored data, of this filtration unit in a storeroom at the Dreadnought Study Collection Centre.

\section{CONCLUSIONS}

Three main pollution control strategies for preventive conservation have been described in this paper. Some of these can be implemented immediately, whilst others require further investigation. The most appropriate pollution strategy for a given museum will depend on the following:

(i) the existing fabric and services of the building

(ii) the susceptibility of objects to particular pollutant degradation

(iii) internal pollutant sources

(iv) the display strategy of the museum: open display or behind glass?

(v) the available resources to install and maintain the most appropriate pollutant control strategy.

Environmental control has both capital and operational costs. For example, airconditioning normally doubles the energy costs of a gallery from $£ 6$ to $£ 12$ (1991) per year per $\mathrm{m}^{2}$ of floor area and maintenance costs can be as high as $£ 20$ per $\mathrm{m}^{2}$ [16]. Over the lifetime of a building the operational costs of air-conditioning will exceed the capital costs.

There is considerable potential to improve current practices in pollutant control. The aim of this paper has been to begin to measure the impact of different interventions that museums may wish to investigate. Work currently in progress will also help to measure in more detail the relative costs and benefits of different interventions including their sustainability. 


\section{ACKNOWLEDGEMENTS}

The research presented in this paper was instigated by the Museums \& Galleries Commission and is being carried out in conjunction with The Bartlett School of Graduate Studies, University College London and EMCEL Filters Ltd. It has been funded by the UK Government's Department of the Environment, Transport and the Regions' Partners in Innovation Programme, EMCEL Filters Ltd and the Horniman Museum with case study buildings provided by the Museum of London, the Victoria \& Albert Museum, The Manchester Museum and the Horniman Museum. Without this multidisciplinary approach and the involvement of end-users, researchers and industry, co-ordinated by a strategic body representing end-users, this research would not have been possible. However, the views expressed in this paper are solely those of the authors. 


\section{REFERENCES}

[1] Eggleston, S., Hackman, M.P., Heyes, C.A., Irwin, J.G., Timmis, R.J. and Williams, M.L.

'Trends in urban air pollution in the United Kingdom during recent decades', Atmospheric Environment 26B (2) (1992) 227-239.

[2] Watts, S.F. and Roberts, C.N. 'Hydrogen sulphide from car catalytic converters', Atmospheric Environment 33 (1) (1999) 169-170.

[3] Chartered Institute of Building Services Engineers. Guide A, Environmental Design (1999) CIBSE, London.

[4] Thomson, G. The Museum Environment, (1986) 2nd ed. Butterworths, London.

[5] BS5454:1989 Recommendations for storage and exhibition of archival documents, (1989) British Standards Institute, London.

[6] Cassar, M., Blades, N. and Oreszczyn, T. 'Air pollution levels in air-conditioned and naturally ventilated museums: a pilot study' in Preprints of the ICOM Committee for Conservation 12th Triennial Meeting, Lyon, 29 August - 3 September 1999, Vol. 1., (1999) 3137, James \& James, London.

[7] Colls, J. Air Pollution - An introduction, (1997) $1^{\text {st }}$ ed. E\&FN Spon, London.

[8] Spedding, D.J. Atmospheric Environment 20 (1969) 341.

[9] Spedding, D.J. and Rowlands, R.P. 'Sorption of sulphur dioxide by indoor surfaces. I. Wallpapers', Journal of Applied Chemistry, 20 (1970) 143-146.

[10] Spedding, D.J. 'Sorption of sulphur dioxide by indoor surfaces. II. Wood' Journal of Applied Chemistry 20 (1970) 226-228.

[11] Spedding, D.J. 'Sorption of sulphur dioxide by indoor surfaces - III. Leather', Journal of 
Applied Chemical Biotechnology, 21(1971) 68-70.

[12] Weschler, C.J., Shields, H.C. and Naik, D.V. 'Indoor ozone exposures', Journal of the Air Pollution Control Association, 39 (12) (1989) 1562-1568.

[13] Booth, W., Potter, I.N. and Jones, T.J. Location of ventilation air intakes, Report 77940/1, (1996) Building Services Research and Information Association, Bracknall.

[14] Chartered Institute of Building Services Engineers. Minimising pollution at air intakes, Technical Memorandum TM21, (1999) CIBSE, London.

[15] Oreszczyn, T., Cassar, M. and Fernadez, K. 'Comparative study of air-conditioned and nonair-conditioned museums' in Preprints of the Contributions to the Ottawa Congress, 12-16 September 1994, Preventive Conservation: Practice, Theory and Research. (1994) 144-148. International Institute of Conservation, London.

[16] ibid. 


\section{FIGURE CAPTIONS}

Figure 1. Effect of ventilation rate on $\mathrm{I} / \mathrm{O}$ nitrogen dioxide ratios for various naturally ventilated museum types. Predicted using the steady state pollution model in equation (1).

Figure 2. Nitrogen dioxide I/O ratios for air-conditioned sites with and without carbon filtration. Data measured using diffusion tubes.

Figure 3. Effect of degree of recirculation on nitrogen dioxide $\mathrm{I} / \mathrm{O}$ ratios in an air-conditioned carbon-filtered museum at various infiltration (leakage) rates. Predicted using the steady state pollution model in equation (1), which has been modified to take active filtration into account. The graph is calculated using the following assumptions: gallery volume, $3000 \mathrm{~m}^{3}$; average surface deposition velocity for $\mathrm{NO}_{2}, 0.48 \mathrm{mhr}^{-1}$; air conditioning system air change rate, 3.7 ach; carbon filter efficiency, $99 \%$.

Figure 4. Theoretical effect of local filtration unit on the nitrogen dioxide concentration in the Dreadnought Study Collection Centre Fumigation Room. Predicted using the steady state pollution model in equation (1). The following measured parameters were used to calculate the graph: room volume, $300 \mathrm{~m}^{3}$; room natural air exchange rate, 0.75 ach; average surface deposition velocity for $\mathrm{NO}_{2}, 1.94 \mathrm{mhr}^{-1}$.

Figure 5. Measured effect of localised filtration unit on pollutant concentrations in the Dreadnought Study Collection Centre Fumigation Room. Data measured before and after the 
intervention using diffusion tubes. ' $<$ DL' indicates that a pollutant occurred below the detection limit of the analytical method.

\section{AUTHORS}

Although beginning his career as a chemist, Nigel Blades has had a long-term interest in museums and conservation. He obtained a $\mathrm{PhD}$ in archaeological science from the University of London, and in 1993 joined the Victoria and Albert Museum Science Section, as a researcher investigating indoor air pollution. Having worked also at the School of Environmental Sciences, University of East Anglia, he is now a Research Fellow at the Bartlett School of Graduate Studies, where his main interest continues to be the museum environment.

Address: The Bartlett School of Graduate Studies, University College London, Gower Street, London WC1E 6BT, UK.

May Cassar MSc, FIIC, AMUKIC is Environmental Advisor at the Museums \& Galleries Commission. She is a conservator and environmental engineer and has been responsible for the last ten years in raising awareness and improving the level of knowledge among the UK's museums and galleries of issues relating to sustainable environmental management in buildings. Address: Museums \& Galleries Commission, 16 Queen Anne’s Gate, London SW1H 9AA, UK. 
Tadj Oreszczyn PhD, CEng, MCIBSE MInstE is Professor of Energy and Environment and Director of Environmental Design and Engineering at the Bartlett School of Graduate Studies, University College London. $\mathrm{He}$ is a Building Scientist and has undertaken research into hygrothermal control and energy use in historic buildings.

Address: The Bartlett School of Graduate Studies, University College London, Gower Street, London WC1E 6BT, UK.

Dr Ben Croxford is a lecturer in Health and Comfort in Buildings, which is part of the MSc in Environmental Design and Engineering at the Bartlett, UCL. He has worked on several research projects at the Bartlett investigating distribution of carbon monoxide in streets, air quality in offices and also in dwellings with gas cookers. He has designed and developed the StreetBox instrument for measuring carbon monoxide, and is currently working in a multi-university study modelling the health effects of borough wide strategies to reduce carbon dioxide emissions.

Address: The Bartlett School of Graduate Studies, University College London, Gower Street, London WC1E 6BT, UK. 